\title{
Influence of allelic variations in relation to norepinephrine and mineralocorticoid receptors on psychopathic traits: a pilot study
}

\author{
Guillaume Durand Corresp. 1 \\ ${ }^{1}$ Department of Psychiatry \& Neuropsychology, University of Maastricht, Netherlands \\ Corresponding Author: Guillaume Durand \\ Email address: gdura061@uottawa.ca
}

Background. Past findings support a relationship between abnormalities in the amygdala and the presence of psychopathic traits. Among other genes and biomarkers relevant to the amygdala, norepinephrine and mineralocorticoid receptor might both play a role in psychopathy due to their association with traits peripheral to psychopathy. The purpose is to examine if allelic variations in single nucleotide polymorphisms related to norepinephrine and mineralocorticoid receptor play a role in the display of psychopathic traits and executive functions.

Methods. Fifty-seven healthy participants from the community provided a saliva sample for SNP sampling of rs5522 and rs5569. Participants then completed the Psychopathic Personality Inventory Short Form (PPI-SF) and the Tower of Hanoi.

Results. Allelic variations of both rs5522 and rs5569 were significant when compared to PPI-SF total score and the fearless dominance component of the PPI-SF. A significant result was also obtained between rs5522 and the number of moves needed to complete the 5-disk Tower of Hanoi.

Conclusion. This pilot study offers preliminary results regarding the effect of allelic variations in SNPS related to norepinephrine and mineralocorticoid receptor on the presence of psychopathic traits. Suggestions are provided to enhance the reliability and validity of a larger-scale study. 
2 Influence of allelic variations in relation to norepinephrine and mineralocorticoid receptors on

3 psychopathic traits: a pilot study

4

5 Guillaume Durand ${ }^{1}$

$6{ }^{1}$ Department of Psychiatry \& Neuropsychology, Maastricht University, P.O. Box 616,

7 Maastricht $6200 \mathrm{MD}$, Maastricht, The Netherlands.

8

9 Correspondence:

10 Guillaume Durand

11 E-mail: gdura061@uottawa.ca

12

13

14

15

16

17

18

19 


\section{Abstract}

21

22

23

24

25

26

27

Background. Past findings support a relationship between abnormalities in the amygdala and the presence of psychopathic traits. Among other genes and biomarkers relevant to the amygdala, norepinephrine and mineralocorticoid receptor might both play a role in psychopathy due to their association with traits peripheral to psychopathy. The purpose is to examine if allelic variations in single nucleotide polymorphisms related to norepinephrine and mineralocorticoid receptor play a role in the display of psychopathic traits and executive functions.

7 Methods. Fifty-seven healthy participants from the community provided a saliva sample for SNP sampling of rs5522 and rs5569. Participants then completed the Psychopathic Personality Inventory - Short Form (PPI-SF) and the Tower of Hanoi.

Results. Allelic variations of both rs5522 and rs5569 were significant when compared to PPI-SF total score and the fearless dominance component of the PPI-SF. A significant result was also obtained between rs5522 and the number of moves needed to complete the 5-disk Tower of Hanoi.

Conclusion. This pilot study offers preliminary results regarding the effect of allelic variations in SNPs related to norepinephrine and mineralocorticoid receptor on the presence of psychopathic traits. Suggestions are provided to enhance the reliability and validity of a larger-scale study. 


\section{1. Introduction}

42 Psychopathy is commonly defined as a personality condition characterized by an absence of

43 emotional empathy, impulsivity, callousness, and manipulative behaviors (Berg et al., 2013; Gao

44 \& Tang, 2013; López, Poy, Patrick, \& Moltó, 2013). Although the causes of psychopathy are

45 unknown, research supports a combined influence of genetic, environmental, and developmental

46 factors (Berg et al., 2013). A meta-analysis of twin studies in the field of psychopathy supports a

47 considerable $(29-56 \%)$ genetic influence on psychopathic traits (Rhee \& Waldman, 2002).

48 While there is an ongoing debate regarding the brain structures the most relevant in psychopathy,

previous findings support the role of a paralimbic system dysfunction as a central component of psychopathy (Blair, 2007; Hyde, Byrd, Votruba-Drzal, Hariri, \& Manuck, 2014; Yoder, Porges,

\& Decety, 2015). A literature review identified implications between psychopathy and orbital

frontal cortex, insula, anterior and posterior cingulated, parahippocampal gyrus, anterior superior temporal gyrus, and amygdala (Kiehl, 2006). Among these structures, there is a relative consensus that a dysfunctional amygdala (i.e. a lack of activation in the amygdala during fMRI scans in psychopathic individuals on tasks related to psychopathy, such as empathy) plays a major role in psychopathy (Blair \& Mitchell, 2009). In their review, Blair and Mitchell (2009) highlight that the theory of a dysfunctional amygdala is supported by data indicating reduced emotional attention in psychopathy. Furthermore, the literature suggests that psychopathy is associated with numerous core functional impairments, such as deficits in aversive conditioning, augmentation of the startle reflex by visual threat primes and fearful expression recognition (Blair, 2007). These impairments are also seen following lesions of the amygdala (Blair, 2006). However, since psychopathy is not a neurological condition, nor is it associated with cerebral lesions, other factors, such as biomarkers, may play a role in the expression of psychopathy. 
64 Various biomarkers have been associated with the display of psychopathic traits, such as cortisol 65 and testosterone (Glenn, 2009). Out of these biomarkers, norepinephrine (NE) has received

66 considerable attention due to its role in emotional processing of the amygdala (Chrousos \& Gold, 1992; McGaugh, 2000). A past study investigated the effect of betablocker (propranolol; a noradrenergic antagonist), using highly emotional stimuli (Van Stegeren et al., 2005). The authors monitored amygdala activation with fMRI during encoding of sets of pictures between participants on the betablocker and those on placebo. The findings support the role of NE in amygdala activation. Indeed, neutral and very light emotional pictures did not activate the amygdala significantly compared to baseline level, while negative emotional pictures resulted to a significant increase in amygdala activation, but only under the placebo condition. When both central and peripheral noradrenergic receptors were 'blocked' using propranolol, amygdala activation decreased when participants were presented emotional stimuli. These results go in line with previous findings linking NE and aggressive behaviors (Craig \& Halton, 2009). Indeed, beta-type noradrenergic receptor blockers have also been used to control aggressive behavior in violent individuals (Yudofsky, Silver, \& Hales, 1998). These findings suggest that genetic variation in the NE receptors may be important in aggression responses. Additionally, previous reports suggest that antisocial individuals have lower baseline levels of NE, which is also a hallmark of increased aggression (Perez, 2012). Altogether, these findings indicate a potential relationship between psychopathic traits and dysfunctional NE secretion.

In addition to NE, the mineralocorticoid receptor (MR) might play a central role in psychopathy due to its effect in peripheral traits of psychopathy (i.e. traits that may not be present in every psychopathic individuals, such as boldness and fearlessness, as opposed to core traits which constitute the hallmark of psychopathy, such as disinhibition and meanness) (Lynam et al., 2011; 
87 ter Heegde, De Rijk, \& Vinkers, 2015; Venables, Hall, \& Patrick, 2014). Previous findings

88 support an association between MR and risk taking (Deuter et al., 2017), MR and stress

89 resilience (Ising et al., 2008), and MR and moderation of childhood emotional neglect and

90 amygdala reactivity (Ryan Bogdan, Williamson, \& Hariri, 2012). Although it is highly debated

91 as to if risk taking and heightened levels of stress resilience are core features of psychopathy or

92 components peripheral to the condition (Benning, 2013; Blonigen, 2013; Lilienfeld, 2013;

93 Marcus, Edens, \& Fulton, 2013; Patrick, Venables, \& Drislane, 2013), these traits are

94 nonetheless associated with psychopathy. Indeed, past research identified a relationship between

95 taking risky decision and psychopathic traits (Takahashi, Takagishi, Nishinaka, Makino, \&

96 Fukui, 2014), as well as stress resilience and increase in psychopathic traits (Dunlop et al., 2011;

97 Durand \& Plata, 2017; Uzieblo, Verschuere, Van den Bussche, \& Crombez, 2010).

98 Alternatively, multiple studies reported an association between childhood emotional neglect and

99 the presence of psychopathic traits later in life (Graham, Kimonis, Wasserman, \& Kline, 2012;

100 Watts, Donahue, Lilienfeld, \& Latzman, 2017). While a negative correlation is observed between

101 psychopathic traits related to boldness and self-reported childhood maltreatment, a positive

102 association is observed between traits related to meanness and disinhibition and childhood

103 maltreatment. Based on the interaction between MR genotype and a history of childhood

104 maltreatment, whereas a positive association between emotional neglect and threat-related 105 amygdala reactivity is only observed in iso homozygotes, MR may play a role in moderating or 106 predicting psychopathic traits.

107 In addition to a potential role between MR and psychopathy, MR may be associated with 108 executive functions. Indeed, MR is present in numerous areas such as the dorsal hippocampus, 109 the ventral hippocampus, and the medial prefrontal cortex. Furthermore MR has been previously 
110 implicated in fear and memory (McEown \& Treit, 2011). A decrease of MR mRNA expression

111 in the prefrontal cortex of schizophrenia and bipolar disorder has also been observed (Xing,

112 Russell, Webster, \& Post, 2004). Considering the role of the prefrontal cortex in psychopathy,

113 which is mostly due to the ventromedial and anterior cingulated sectors, theorized to mediate

114 numerous social and affective decision-making functions, it is possible that there is an interaction

115 between MR, executive functions, and psychopathy (Koenigs, 2012). However, previous

116 findings have obtained contradictory results regarding the type of association between executive

117 functions and psychopathy. One study concluded that psychopaths who had never been

118 convicted for a crime performed better than psychopaths who have previously been convicted

119 and non-psychopathic individuals on the Wisconsin Card Sorting Test (WCST) (Ishikawa,

120 Raine, Lencz, Bihrle, \& Lacasse, 2001). A second study concluded that higher levels of

121 psychopathic traits were negatively correlated with various executive functions, such as

122 inhibition, working memory, and planning (Lantrip, Towns, Roth, \& Giancola, 2016). These

123 findings were however moderated when examining the results by psychopathic subtypes,

124 whereas traits related to fearless dominance were correlated with better executive functions,

125 while traits related to antisocial and impulsivity were correlated with worse executive functions.

126 Another study reported that highly psychopathic individuals performed similarly to low and

127 middle psychopathy groups on a manual version of the Tower of Hanoi, while performing better

128 than those two groups on a computerized version of the task, which requires working memory,

129 planning, and inhibition (Salnaitis, Baker, Holland, \& Welsh, 2011). While the interaction effect

130 between psychopathy groups and modality of the task is unclear, the results provide insights

131 regarding a potential relationship between psychopathic individuals and planning abilities.

132 Considering the supposed relationship between NE and MR on psychopathy, and the link 
133 between psychopathy and cognitive functions, it might also be possible to observe a role of NE

134 or MR on cognitive abilities.

135 To the author's knowledge, no study has explicitly investigated the relationship between NE and

136 MR from a genetic point of view, and their relationship with psychopathic traits and executive

137 functioning. Genetic studies being increasingly expensive, a preliminary study in a healthy

138 sample is needed to confirm the expected relationship between the aforementioned variables

139 before engaging in a costly and time consuming larger scale study. Hence, the purpose of this

140 pilot study is to establish a paradigm for a future study assessing the role of genetic variations in

141 relation to $\mathrm{NE}$ and $\mathrm{MR}$ in the presence of psychopathic traits and cognitive abilities. I first

142 hypothesize a correlation between psychopathic traits and cognitive abilities. I also hypothesize a

143 difference between NE and MR SNPs and psychopathic traits. Lastly, I hypothesize a difference

144 between NE and MR SNPs and cognitive abilities. To this end, two single nucleotide

145 polymorphisms (SNP) were selected: the rs5522 of the MR gene NR3C2, and the rs5569 from

146 the SLC6A2, which is a NE transporter. Rs5522 was selected due to its past association with

147 enhanced physiological stress response and reduced cortisol-induced MR gene expression, two

148 components which can be associated to psychopathy (R. Bogdan, Perlis, Fagerness, \& Pizzagalli,

149 2010). Alternatively, rs5569 was selected as it is one of the most common SNP studied when

150 examining the SLC6A2 gene (Bruxel et al., 2014; Miguita, Cordeiro, Shavitt, Miguel, \& Vallada,

151 2006; Retz et al., 2008; Sun et al., 2008)

152 2. Methods

$1532.1 \quad$ Participants 
154 A total of 57 healthy participants (Males $=30$, Females $=27$ ) were recruited via advertisements

155 on social media, on university campus, and on site at a firefighter department to take part in the

156 current study. DNA was collected using saliva sampling at the day of assessments. The age of

157 the participants ranged between 18 to 59 years old $(M=34.51, S D=14.91)$. Participants were

158 recruited from universities $(N=25)$, fire departments $(N=12)$, and online community groups $(N$

$159=20$ ). All participants were free of any psychotropic medication for the past 12 months. No

160 participant reported receiving treatment from a health professional for the past 6 months, nor did

161 any participant report a psychiatric or medical diagnosis. The descriptive characteristics of the

162 participants by recruitment location and scores on the tower of Hanoi are provided in Table 1.

163 The current study was approved by the Ethics Review Committee of IntegReview (Austin, TX;

164 Www.integreview.com; protocol number 11122015). All participants received and signed an

165 informed consent form with detailed information about the nature, the goal, the procedure and

166 possible consequences of the study prior starting the experiment. All participants' information

167 was kept anonymous during the courses of the whole experimental process and analyses.

168 Participants received $10 \$$ as compensation for their time.

$169 \quad 2.2 \quad$ Measurements

170 2.2.1 Psychopathic Personality Inventory - Short Form

171 The Psychopathic Personality Inventory - Short Form (PPI-SF) is a 56-item self-report 172 questionnaire derived from the original 187-item PPI (Lilienfeld \& Widows, 2005). The PPI-SF

173 assesses psychopathic traits through eight subscales, namely: Machiavellian Egocentricity,

174 Social Potency, Fearlessness, Coldheartedness, Impulsive Nonconformity, Blame

175 Externalization, Carefree Nonplanfulness, and Stress Immunity. The questionnaire is rated on a

176 Likert scale ranging from $1=$ False to $4=$ True. Seven of the eight subscales are divided into 
177 two factors, namely Fearless Dominance (PPI-I) and Impulsive Antisociality (PPI-II). While

178 Coldheartedness does not load on neither of these factors, it is included in the total score. PPI-I

179 focuses on adaptive traits (social poise, fearlessness, stress immunity), while PPI-II focuses on 180 maladaptive traits (manipulative tendencies, callousness, lack of empathy, impulsivity). A higher 181 score correspond to higher levels of psychopathic traits.

182 2.2.2 The Tower of Hanoi

183 The Tower of Hanoi is a problem-solving task measuring executive functioning. Although 184 principally focusing on planning abilities, the task also requires working memory, inhibition, 185 problem solving, and goal-directed behavior (Salnaitis et al., 2011). The goal of the puzzle is to 186 displace a set of disks, five in the current study, from the middle rod to the first or third rod, 187 while following three rules: (1) never move two disks at the same time, (2) only move the upper 188 disk of the stack and (3) never place a bigger disk on a smaller disk. A previous study has 189 determined that this puzzle act on the participant capacity to plan ahead, which is correlated with 190 the frontal lobe functioning (Goel \& Grafman, 1995). The task is over once the participant has 191 successfully completed the puzzle, or after 5 minutes. The algorithm of the puzzle forces 192 participants to complete a tower of 3 disks and a tower of 4 disks before completing the tower of 1935 disks. The minimum number of moves to complete the 3 -disk tower is 7,15 for the 4 -disk 194 tower and 31 for the 5-disk tower. Scoring is performed by calculating the number of stack 195 completed, the number of moves needed to complete each stack, and the time needed to 196 complete the 5-disk tower among individuals who completed it.

$197 \quad 2.3 \quad$ Sample DNA extraction 
198 The selected SNPs were processed via a Sequenom panel for multiplex reaction and genotyping

199 at McGill University (McGill University and Génome Québec Innovation Centre, Québec,

200 Canada). DNA Extraction was done using the prepIT-L2P from DNA Genotek (item \#PT-L2P-

$20145)$ according to the manufacturer's protocol. A multiplex PCR was performed on $20 \mathrm{ng}$ of

202 template genomic DNA in a $5 \mathrm{uL}$ reaction mixture containing: $0.1 \mathrm{uL}(0.5 \mathrm{U})$ HotStar Taq

203 enzyme (QIAGEN), $0.625 \mathrm{uL}$ of 10X HotStar Buffer, $0.325 \mathrm{uL}$ of $25 \mathrm{mM}$ (total) MgCl2, $0.25 \mathrm{uL}$

204 of $10 \mathrm{mM}$ dNTP mix, $0.55 \mathrm{uL}$ of forward and reverse primer pool $(1 \mathrm{uM})$ and $1.15 \mathrm{uL}$ of water.

205 The amplification cycling used was: 95c $15 \mathrm{~min}, 45 \mathrm{x}$ (95c $20 \mathrm{sec}, 56 \mathrm{c} 30 \mathrm{sec}, 72 \mathrm{c} 60 \mathrm{sec}), 72 \mathrm{c} 3$

206 min, hold 4c. A few PCR reactions were run on QIAxcel (QIAGEN) to assess the amplification

207 (1 uL of PCR in $9 \mathrm{uL}$ of DNA Dilution Buffer (QIAGEN)). This was followed by a shrimp-

208 alkaline-phosphatase treatment to render the leftover nucleotides unusable $(0.2 \mathrm{uL}$ of SAP

209 Buffer, $0.3 \mathrm{uL}$ of SAP and $1.5 \mathrm{uL}$ of water). SAP cycling: 37c $40 \mathrm{~min}, 85 \mathrm{c} 10 \mathrm{~min}$, hold 4c.

210 Next, a primer extension reaction (iPLEX Gold) was performed with $0.94 \mathrm{uL}$ of extension primer

211 mix, $0.2 \mathrm{uL}$ of iPLEX Terminator, $0.2 \mathrm{uL}$ of iPLEX Buffer, $0.041 \mathrm{uL}$ of iPLEX Thermo

212 Sequenase and $0.619 \mathrm{uL}$ of water. The products were desalted using $6 \mathrm{mg}$ of resin (Agena

213 Bioscience) and spotted on a 384-point SpectroCHIP (Agena Bioscience) using a nanodispenser.

214 The distinct masses were determined by MALDI-TOF mass-spectrometry and data was analyzed

215 using MassARRAY Typer Analyser software.

\section{$2162.4 \quad$ Experimental Procedure}

217 Upon the candidates' arrival to the laboratory, the participants were asked to sign the consent

218 form. The candidates were asked to answer demographic information and a saliva sample was

219 collected. The participants then completed the PPI-SF. Upon completion of the questionnaire, the

220 participants completed the Tower of Hanoi. 


\section{$221 \quad 2.5 \quad$ Statistical analysis}

222 All analyses were performed using the Statistical Package SPSS version 23.00. Identification of 223 dominant and recessive alleles for the two SNPs was performed using refSNP 224 (www.ncbi.nlm.nih.gov/snp/). A dominant model was used for both rs5522 (AA = 1, Ag or gg = $2250)$ and $\mathrm{rs} 5569(\mathrm{CC}=1, \mathrm{Ct}$ or $\mathrm{tt}=0)$. A series of ANOVA were performed on both SNPs and the 226 various dependent variables.

$227 \quad 3 . \quad$ Results

\section{3.1 Psychopathic traits and planning abilities}

229 A Pearson correlation between each component of the PPI-SF (PPI-SF Total, PPI-I, and PPI-II) 230 and the variables associated with the Tower of Hanoi (number of moves to complete each towers 231 and time to complete the 5-disk tower of Hanoi among those who completed it) did not yield any 232 significant result.

\section{$233 \quad 3.2 \quad$ SNPs and psychopathic traits}

234 As shown in Figure 1 to 4, two significant differences were observed on both SNPs. On rs5522, 235 AA alleles carriers displayed higher scores on PPI-SF Total $(\mathrm{M}=123.72, \mathrm{SD}=12.29)$ than $236 \mathrm{AG} / \mathrm{GG}$ alleles carriers $(\mathrm{M}=115.57, \mathrm{SD}=10.57)(F(1,56)=4.946, p=.030)$. Additionally, AA 237 alleles carriers also displayed higher scores on PPI-I $(\mathrm{M}=54.27, \mathrm{SD}=7.84)$ than AG/GG alleles carriers $(\mathrm{M}=48.42, \mathrm{SD}=7.89)(F(1,56)=5.855, p=.019)$. On rs5569, CC alleles carriers

239 displayed lower scores on PPI-SF Total $(\mathrm{M}=118.00, \mathrm{SD}=11.03)$ than $\mathrm{CT} / \mathrm{TT}$ alleles carriers $240(\mathrm{M}=125.57, \mathrm{SD}=12.57)(F(1,56)=5.845, p=.019)$. Lastly, $\mathrm{CC}$ alleles carriers also displayed 241 lower scores on PPI-I $(\mathrm{M}=49.75, \mathrm{SD}=8.01)$ than $\mathrm{CT} / \mathrm{TT}$ alleles carriers $(\mathrm{M}=56.03, \mathrm{SD}=$ 242 7.19) $(F(1,56)=9.659, p=.003)$. 


\section{$243 \quad 3.3 \quad$ SNPS and planning abilities}

244 As shown in Figure 5, only one significant result emerged from a series of ANOVA comparing

245 the two SNPs with scores obtained on the Tower of Hanoi. Within participants who completed

246 the last level of the Tower of Hanoi, AA carriers from rs5522 completed the puzzle in less moves

$247(\mathrm{M}=48.38, \mathrm{SD}=13.62)$ than $\mathrm{AG} / \mathrm{GG}$ alleles carriers $(\mathrm{M}=60.82, \mathrm{SD}=23.35)(F(1,44)=$

$248 \quad 4.772, p=.034)$.

249 4. Discussion

250 This study examined the relationship between the allelic variations in two SNPs related to NE

251 and MR in relation to psychopathic traits and executive functioning. Preliminary support was

252 found for a relationship between both SNPs on PPI-SF total scores and PPI-I, as well as for an

253 association between MR and planning abilities as assessed by the Tower of Hanoi.

254 Several conclusions can be drawn from the results of this pilot study. First, despite the low

255 number of participants, most results were well under the threshold of $p<.05$ to establish

256 significance. However, while the results were particularly encouraging regarding rs5569 due to

257 its two groups including almost 30 participants each, and its particularly low $p$ value of .003 for

258 PPI-I, the results regarding rs5522 should be taken with cautions, mostly due to the low number

259 of participants in the non-dominant group $(N=14)$. Second, while multiple significant results

260 were obtained regarding psychopathic traits, only one significant result emerged for executive

261 functions. While the difference in rs5522 on the number of moves needed to complete the Tower

262 of Hanoi was significant at $p=.034$, the non-dominant group only had 11 participants, which is

263 fairly low to provide solid assumptions. Considering no other results emerged between the two

264 SNPs and the Tower of Hanoi, the results indicate that a future study should provide an 
265 alternative method to assess executive functions. These results are in line with a previous study,

266 supporting that the effect of psychopathic traits and scores on the Tower of Hanoi was significant

267 for the computerized version of the task, but not on the manual version (Salnaitis et al., 2011).

268 However, the results between psychopathic traits and executive functions were inconclusive.

269 Despite the expected association between higher psychopathic traits and better results at the

270 Tower of Hanoi, no significant association was observed.

271 This pilot study possesses several limitations. First, the low numbers of participant created

272 uneven groups for rs5522. Second, only one cognitive task, namely the Tower of Hanoi, was

273 used in the present study. Considering the failure to provide adequate results, the future study

274 should focus on an alternative task to measure planning abilities, as well as additional tasks to

275 measure other aspects of executive functions, such as short term memory and behavioral

276 inhibition. Third, the participant pool is largely heterogeneous, with three distinct groups.

277 Although a combination of students, firefighters, and adults browsing the web can arguably be

278 more representative of the community as opposed to a single homogenous group of students,

279 focusing on a single group might provide better results.

\section{5. Conclusion}

281 Based upon these results, several aspects of this experimental design should be modified for

282 future research. First, while the PPI-SF is a valid alternative to the long version of the PPI, it

283 remains a shorten version of the original instrument. A complete version of an instrument

284 assessing psychopathic traits, comparable in size to the PPI-SF, might provides better results. For

285 instance, the Triarchic Psychopathy Measure (TriPM; Patrick, 2010), assesses psychopathic in

286 three different components, namely Boldness, Disinhibition, and Meanness, which correlates to

287 PPI-I, PPI-II, and Coldheartedness respectively. Past findings further support the incremental 
288 validity of the TriPM over the PPI-SF (Stanley, Wygant, \& Sellbom, 2013). Second, the Tower

289 of Hanoi did not provide the expected results. Due to the small effect size anticipated between 290 allelic variations and executive functions, a complete battery of cognitive testing might be 291 necessary to obtain further data regarding the relationship between those constructs. Third, I 292 solely examined one SNP per area of interest, namely NE and MR. Although those two SNPs 293 were significant, examining additional SNP, in addition to those examined in the present study, 294 known to be related to NE and MR might further strengthen the conclusion of a relationship 295 between psychopathic traits and NE and MR. Fourth, additional questionnaires should be used in 296 conjunction to tests measuring psychopathic traits, such as measures of depressive behavior and 297 anxiety. This would help determine if the results can be explained by other variables than 298 psychopathic traits. These modifications to the experimental design should be sufficient for a 299 large-scale study assessing the genetic variability and the display of psychopathic traits, in 300 relation to executive functioning. 


\section{Reference list}

311 Benning, S. D. (2013). Heterogeneity in content and psychopathies: comment on Marcus et al. Personality Disorders, 4(1), 83-4. https://doi.org/10.1037/a0027451

Berg, J. M., Smith, S. F., Watts, A. L., Ammirati, R., Green, S. E., \& Lilienfeld, S. O. (2013). research. Neuropsychiatry, 3, 63-74. https://doi.org/10.2217/npy.12.69

Blair, R. J. R. (2006). The emergence of psychopathy: Implications for the neuropsychological

Blair, R. J. R., \& Mitchell, D. G. V. (2009). Psychopathy, attention and emotion. Psychological

Blair, R. J. R. (2007). The amygdala and ventromedial prefrontal cortex in morality and psychopathy. Trends in Cognitive Sciences, 11(9), 387-392. https://doi.org/10.1016/j.tics.2007.07.003

Blonigen, D. M. (2013). Is fearless dominance relevant to the construct of psychopathy? approach to developmental disorders. Cognition, 101(2), 414-442. https://doi.org/10.1016/j.cognition.2006.04.005 Medicine, 39(4), 543-55. https://doi.org/10.1017/S0033291708003991 Reconciling the dual roles of theory and clinical utility. Personality Disorders, 4(1), 87-8. https://doi.org/10.1037/a0027152

Bogdan, R., Perlis, R. H., Fagerness, J., \& Pizzagalli, D. A. (2010). The impact of mineralocorticoid receptor ISO/VAL genotype (rs5522) and stress on reward learning. Genes, Brain and Behavior, v(2), no-no. https://doi.org/10.1111/j.1601-183X.2010.00600.x 
330 Bogdan, R., Williamson, D. E., \& Hariri, A. R. (2012). Mineralocorticoid Receptor Iso/Val

331 (rs5522) Genotype Moderates the Association Between Previous Childhood Emotional

332 Neglect and Amygdala Reactivity. American Journal of Psychiatry, 169(5), 515-522.

333 https://doi.org/10.1176/appi.ajp.2011.11060855

334 Bruxel, E. M., Akutagava-Martins, G. C., Salatino-Oliveira, A., Contini, V., Kieling, C., Hutz,

335 M. H., \& Rohde, L. A. (2014). ADHD pharmacogenetics across the life cycle: New findings

336 and perspectives. American Journal of Medical Genetics, Part B: Neuropsychiatric

337 Genetics, 165(4), 263-282. https://doi.org/10.1002/ajmg.b.32240

338 Chrousos, G. P., \& Gold, P. W. (1992). The concepts of stress and stress system disorders.

339 Overview of physical and behavioral homeostasis. JAMA: The Journal of the American

$340 \quad$ Medical Association, 267(9), 1244-1252. https://doi.org/10.1001/jama.267.9.1244

Craig, I. W., \& Halton, K. E. (2009). Genetics of human aggressive behaviour. Human Genetics, 126(1), 101-113. https://doi.org/10.1007/s00439-009-0695-9

Deuter, C. E., Wingenfeld, K., Schultebraucks, K., Hellmann-Regen, J., Piber, D., \& Otte, C. (2017). Effects of mineralocorticoid-receptor stimulation on risk taking behavior in young healthy men and women. Psychoneuroendocrinology, 75, 132-140. https://doi.org/10.1016/j.psyneuen.2016.10.018

Dunlop, B. W., DeFife, J. A., Marx, L., Garlow, S. J., Nemeroff, C. B., \& Lilienfeld, S. O. (2011). The effects of sertraline on psychopathic traits. International Clinical Psychopharmacology, 26(6), 329-37. https://doi.org/10.1097/YIC.0b013e32834b80df

Durand, G., \& Plata, E. M. (2017). The effects of psychopathic traits on fear of pain , anxiety, and stress. Personality and Individual Differences, 119(C), 198-203. 
353 Gao, Y., \& Tang, S. (2013). Psychopathic personality and utilitarian moral judgment in college 354 students. Journal of Criminal Justice, 41(5), 342-349. https://doi.org/10.1016/j.jcrimjus.2013.06.012

Glenn, A. L. (2009). Neuroendocrine Markers of Psychopathy. In M. S. Ritsner (Ed.), The Handbook of Neuropsychiatric Biomarkers, Endophenotypes and Genes (Springer S, pp. 59-70). Retrieved from http://www.springerlink.com/index/P541J78755555H35.pdf

Goel, V., \& Grafman, J. (1995). Are the frontal lobes implicated in "planning" functions? Interpreting data from the Tower of Hanoi. Neuropsychologia, 33, 623-642. https://doi.org/10.1016/0028-3932(95)90866-P

Graham, N., Kimonis, E. R., Wasserman, A. L., \& Kline, S. M. (2012). Associations among childhood abuse and psychopathy facets in male sexual offenders. Personality Disorders: Theory, Research, and Treatment, 3(1), 66-75. https://doi.org/10.1037/a0025605

Hyde, L. W., Byrd, A. L., Votruba-Drzal, E., Hariri, A. R., \& Manuck, S. B. (2014). Amygdala reactivity and negative emotionality: divergent correlates of antisocial personality and psychopathy traits in a community sample. Journal of Abnormal Psychology, 123(1), 21424. https://doi.org/10.1037/a0035467

Ishikawa, S. S., Raine, a, Lencz, T., Bihrle, S., \& Lacasse, L. (2001). Autonomic stress reactivity and executive functions in successful and unsuccessful criminal psychopaths from the community. Journal of Abnormal Psychology, 110(3), 423-432. https://doi.org/10.1037/0021-843X.110.3.423

Ising, M., Depping, A.-M., Siebertz, A., Lucae, S., Unschuld, P. G., Kloiber, S., ... Holsboer, F. 
374

375

376

377

378

379

380

381

382

383

384

385

386

387

388

389

390

391

392

393

394

395

(2008). Polymorphisms in the FKBP5 gene region modulate recovery from psychosocial stress in healthy controls. The European Journal of Neuroscience, 28(2), 389-98. https://doi.org/10.1111/j.1460-9568.2008.06332.x

Kiehl, K. A. (2006). A cognitive neuroscience perspective on psychopathy: Evidence for paralimbic system dysfunction. Psychiatry Research, 142(2-3), 107-128. https://doi.org/10.1016/j.psychres.2005.09.013

Koenigs, M. (2012). The role of prefrontal cortex in psychopathy. Reviews in Neuroscience, 23(3), 253-262. https://doi.org/10.1515/revneuro-2012-0036.The

Lantrip, C., Towns, S., Roth, R. M., \& Giancola, P. R. (2016). Psychopathy traits are associated with self-report rating of executive functions in the everyday life of healthy adults. Personality and Individual Differences, 101, 127-131. https://doi.org/10.1016/j.paid.2016.05.051

Lilienfeld, S. O. (2013). Is psychopathy a syndrome? Commentary on Marcus, Fulton, and Edens. Personality Disorders, 4(1), 85-6. https://doi.org/10.1037/a0027544

Lilienfeld, S. O., \& Widows, M. (2005). Psychopathic personality inventory-revised: Professional manual. Lutz, FL: Psychological Assessment Resources.

López, R., Poy, R., Patrick, C. J., \& Moltó, J. (2013). Deficient fear conditioning and selfreported psychopathy: The role of fearless dominance. Psychophysiology, 50(2), 210-218. https://doi.org/10.1111/j.1469-8986.2012.01493.x

Lynam, D. R., Gaughan, E. T., Miller, J. D., Miller, D. J., Mullins-Sweatt, S., \& Widiger, T. a. (2011). Assessing the basic traits associated with psychopathy: development and validation of the Elemental Psychopathy Assessment. Psychological Assessment, 23(1), 108-124. 
397

Marcus, D. K., Edens, J. F., \& Fulton, J. J. (2013). Is it the inventory, the meta-analysis, or the construct? Reply to the comments on Marcus, Fulton, and Edens. Personality Disorders, 4(1), 89-90. https://doi.org/10.1037/a0027219

McEown, K., \& Treit, D. (2011). Mineralocorticoid receptors in the medial prefrontal cortex and hippocampus mediate rats' unconditioned fear behaviour. Hormones and Behavior, 60(5), 581-588. https://doi.org/10.1016/j.yhbeh.2011.08.007

McGaugh, J. L. (2000). Memory--a Century of Consolidation. Science, 287(5451), 248-251. https://doi.org/10.1126/science.287.5451.248

Miguita, K., Cordeiro, Q., Shavitt, R. G., Miguel, E. C., \& Vallada, H. (2006). Association study between the $1287 \mathrm{~A} / \mathrm{G}$ exonic polymorphism of the norepinephrine transporter (NET) gene and obsessive-compulsive disorder in a Brazilian sample [2]. Revista Brasileira de Psiquiatria, 28(2), 158-159. https://doi.org/10.1590/S1516-44462006000200017

Patrick, C. J. (2010). Operationalizing the Triarchic conceptualisation of psychopathy: Preliminary description of brief scales for assessment of boldness, meanness, and disinhibition. PhenX Toolkit Online Assessment Catalog.

Patrick, C. J., Venables, N. C., \& Drislane, L. E. (2013). The role of fearless dominance in differentiating psychopathy from antisocial personality disorder: comment on Marcus, Fulton, and Edens. Personality Disorders, 4(1), 80-2. https://doi.org/10.1037/a0027173

Perez, P. R. (2012). The etiology of psychopathy: A neuropsychological perspective. Aggression and Violent Behavior, 17(6), 519-522. https://doi.org/10.1016/j.avb.2012.07.006 
417 Retz, W., Rösler, M., Kissling, C., Wiemann, S., Hünnerkopf, R., Coogan, A., ... Freitag, C.

418 (2008). Norepinephrine transporter and catecholamine-O-methyltransferase gene variants

419 and attention-deficit/hyperactivity disorder symptoms in adults. Journal of Neural

420 Transmission, 115(2), 323-329. https://doi.org/10.1007/s00702-007-0822-5

421

422

423

424

425

426

427

428

429

430

431

432

433

434

435

436

437

438

Rhee, S. H., \& Waldman, I. D. (2002). Genetic and environmental influences on antisocial behavior: A meta-analysis of twin and adoption studies. Psychological Bulletin, 128(3), 490-529. https://doi.org/10.1037//0033-2909.128.3.490

Salnaitis, C. L., Baker, C. a, Holland, J., \& Welsh, M. (2011). Differentiating Tower of Hanoi performance: interactive effects of psychopathic tendencies, impulsive response styles, and modality. Applied Neuropsychology, 18(1), 37-46. https://doi.org/10.1080/09084282.2010.523381

Stanley, J. H., Wygant, D. B., \& Sellbom, M. (2013). Elaborating on the Construct Validity of the Triarchic Psychopathy Measure in a Criminal Offender Sample. Journal of Personality Assessment, 95(4), 343-350. https://doi.org/10.1080/00223891.2012.735302

Sun, N., Xu, Y., Wang, Y., Duan, H., Wang, S., Ren, Y., ... Zhang, K. (2008). The combined effect of norepinephrine transporter gene and negative life events in major depression of Chinese Han population. Journal of Neural Transmission, 115(12), 1681-1686. https://doi.org/10.1007/s00702-008-0109-5

Takahashi, T., Takagishi, H., Nishinaka, H., Makino, T., \& Fukui, H. (2014). Neuroeconomics of psychopathy: Risk taking in probability discounting of gain and loss predicts psychopathy. Neuroendocrinology Letters, 35(6), 510-517.

ter Heegde, F., De Rijk, R. H., \& Vinkers, C. H. (2015). The brain mineralocorticoid receptor 
439

440

441

442

443

444

445

446

447

448

449

450

451

452

453

454

455

456

457

458

459

460

and stress resilience. Psychoneuroendocrinology, 52(1), 92-110.

https://doi.org/10.1016/j.psyneuen.2014.10.022

Uzieblo, K., Verschuere, B., Van den Bussche, E., \& Crombez, G. (2010). The Validity of the Psychopathic Personality Inventory--Revised in a Community Sample. Assessment, 17(3), 334-346. https://doi.org/10.1177/1073191109356544

Van Stegeren, A. H., Goekoop, R., Everaerd, W., Scheltens, P., Barkhof, F., Kuijer, J. P. A., \& Rombouts, S. A. R. B. (2005). Noradrenaline mediates amygdala activation in men and women during encoding of emotional material. NeuroImage, 24(3), 898-909. https://doi.org/10.1016/j.neuroimage.2004.09.011

Venables, N. C., Hall, J. R., \& Patrick, C. J. (2014). Differentiating psychopathy from antisocial personality disorder: A triarchic model perspective. Psychological Medicine, 44(5), 10051013. https://doi.org/10.1017/S003329171300161X

Watts, A. L., Donahue, K., Lilienfeld, S. O., \& Latzman, R. D. (2017). Gender moderates psychopathic traits' relations with self-reported childhood maltreatment. Personality and Individual Differences, 119, 175-180. https://doi.org/10.1016/j.paid.2017.07.011

Xing, G.-Q., Russell, S., Webster, M. J., \& Post, R. M. (2004). Decreased expression of mineralocorticoid receptor mRNA in the prefrontal cortex in schizophrenia and bipolar disorder. International Journal of Neuropsychopharmacology, 7(2), 143-153. https://doi.org/10.1017/S1461145703004000

Yoder, K. J., Porges, E. C., \& Decety, J. (2015). Amygdala subnuclei connectivity in response to violence reveals unique influences of individual differences in psychopathic traits in a nonforensic sample. Human Brain Mapping, 36(4), 1417-1428. 
$461 \quad$ https://doi.org/10.1002/hbm.22712

462 Yudofsky, S., Silver, J., \& Hales, R. (1998). Treatment of agitation and aggression. In A.

463 Schatzberg \& C. Nemeroff(Eds.), American Psychiatric Press textbook of

464 psychomarmacology (2nd ed., pp. 881-900). Washington, DC: American Psychiatric Press. 
Table $\mathbf{1}$ (on next page)

Demographic characteristics of participants and mean score 


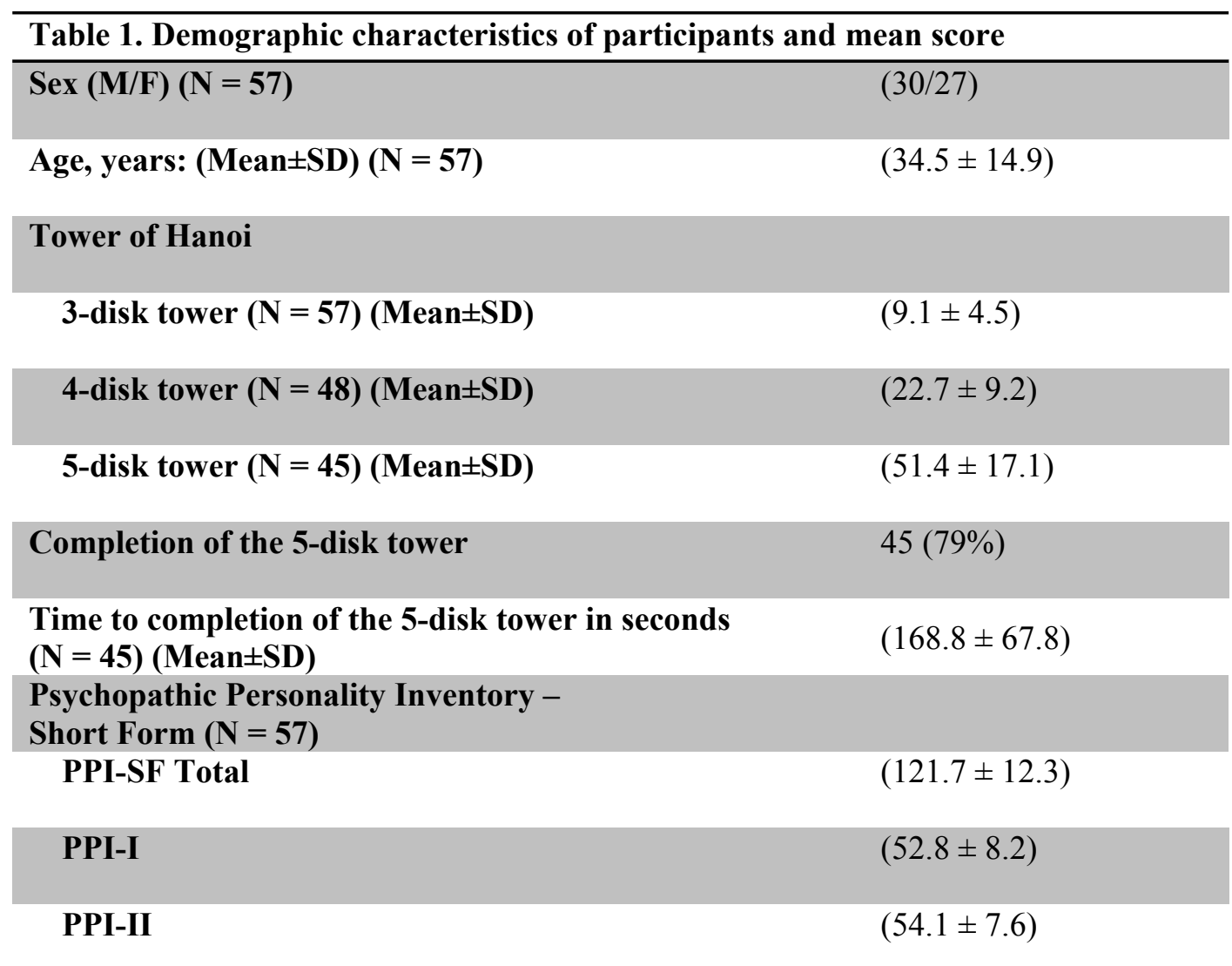

\begin{abstract}
Note. Due to the algorithm of the Tower of Hanoi, participants must complete the 3-disk tower and the 4-disk tower in order to complete the 5-disk tower. Due to the time limitation of 5 minutes, 9 participants were not able to complete the 4-disk tower, and 12 participants (including those of the 4-disk tower) were not able to complete the 5-disk tower. An explanatory video, showing the method to complete the 3-disk, 4-disk, and 5-disk towers is available as a supplementary file.
\end{abstract}


Figure 1

Mean score on the PPI-SF Total, with error bars showing a 95\% confidence interval on rs5522 genotype.

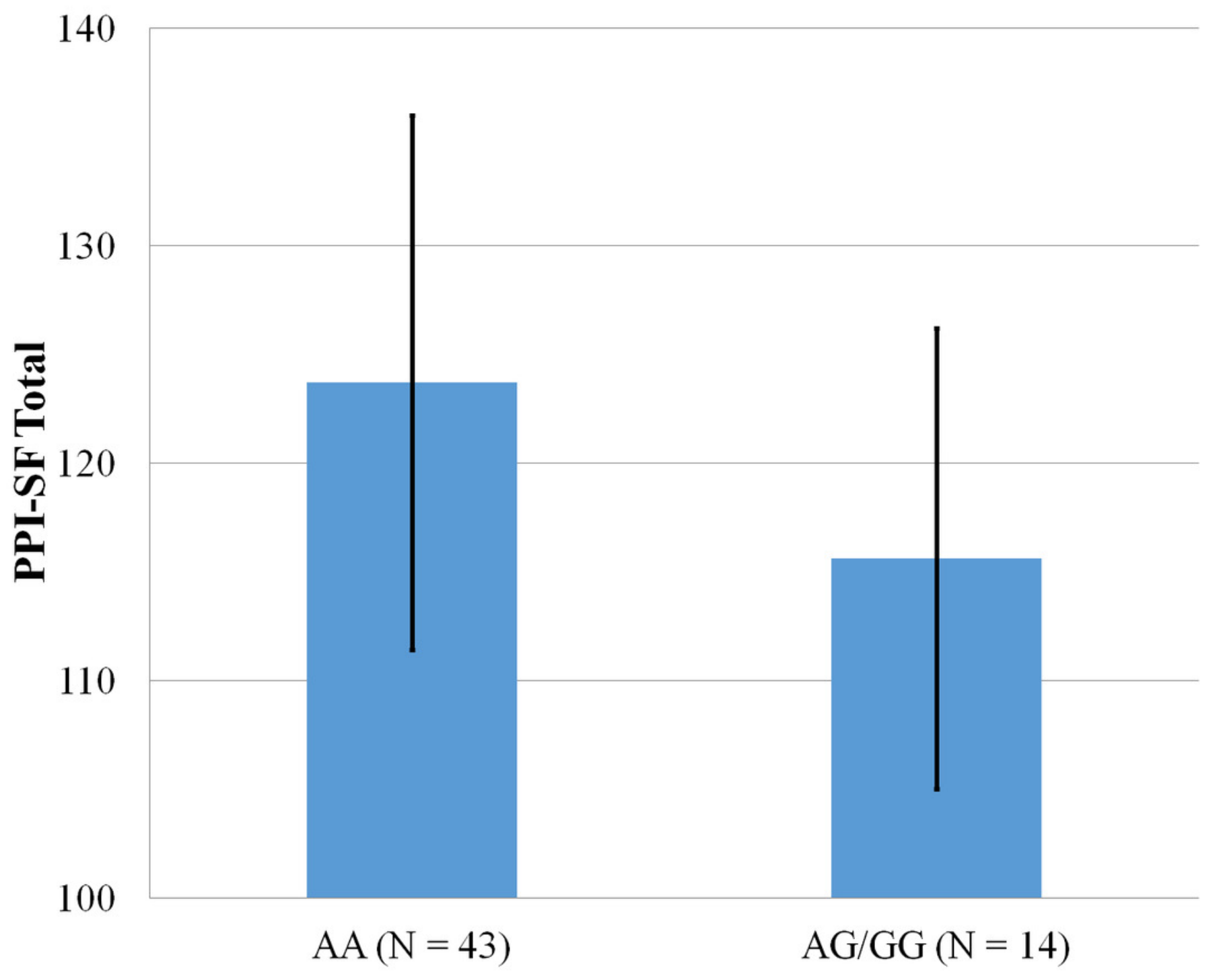


Figure 2

Mean score on the PPI-I, with error bars showing a 95\% confidence interval on rs5522 genotype.

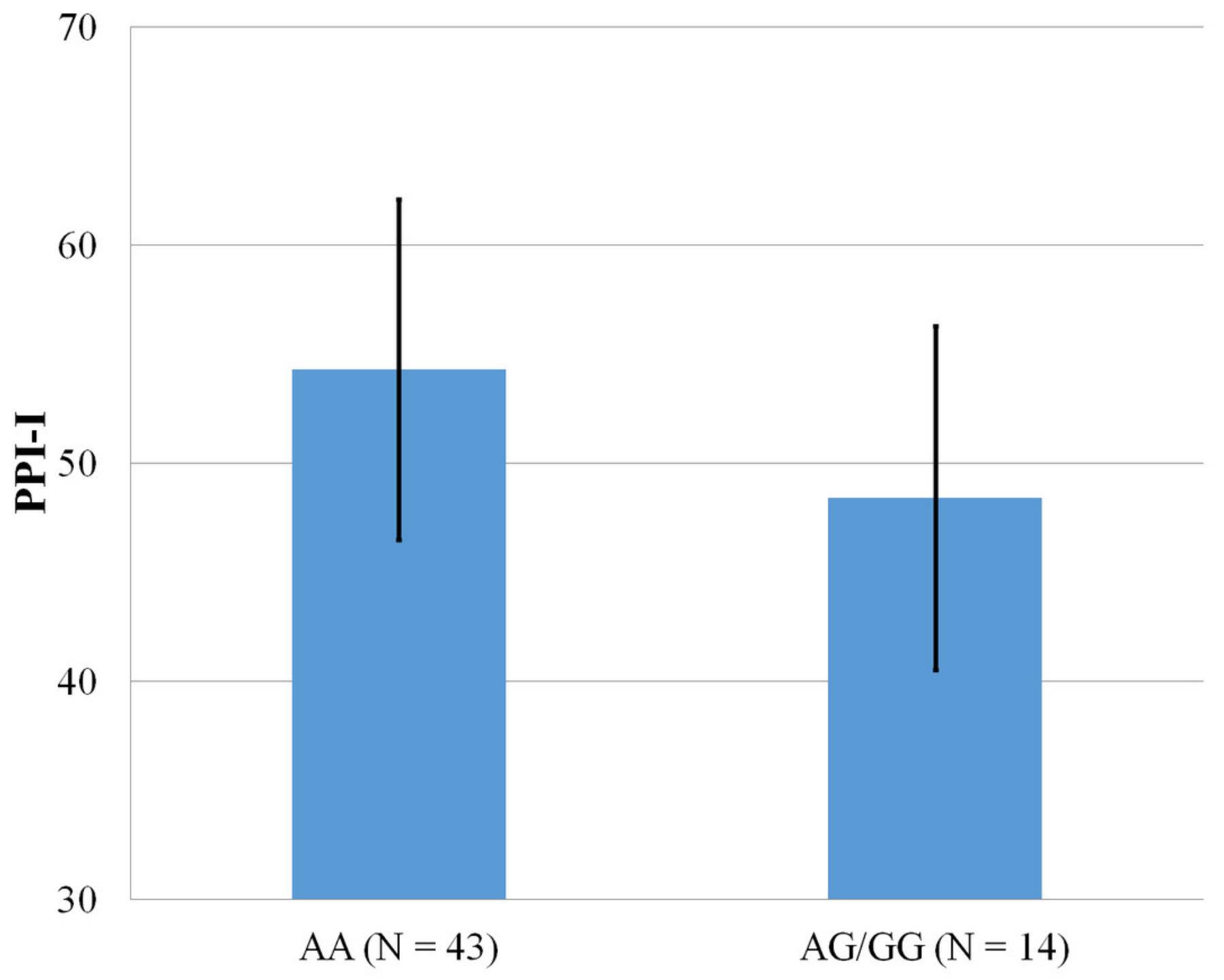


Figure 3

Mean score on the PPI-SF Total, with error bars showing a 95\% confidence interval on rs5569 genotype.

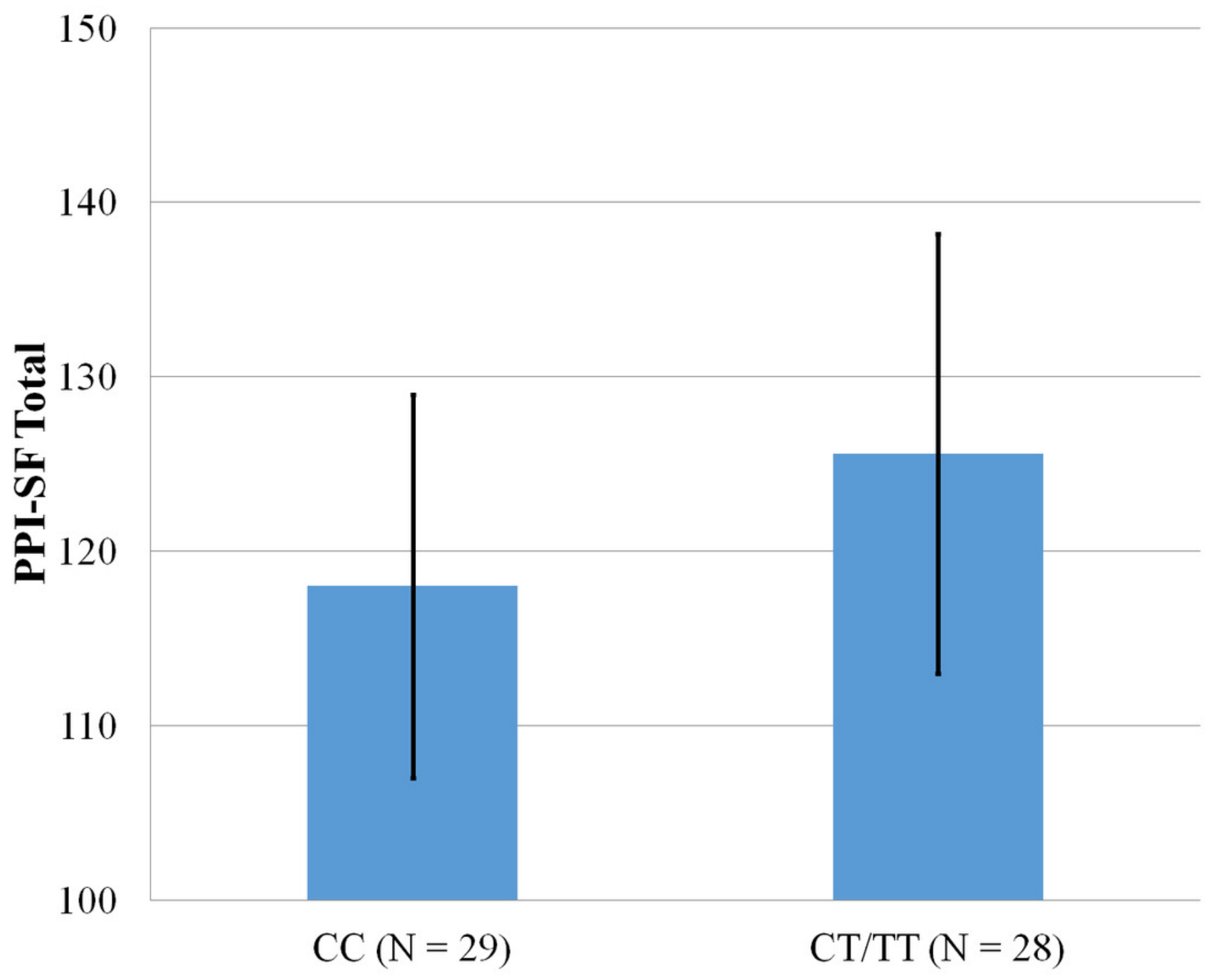


Figure 4

Mean score on the PPI-I, with error bars showing a 95\% confidence interval on rs5569 genotype.

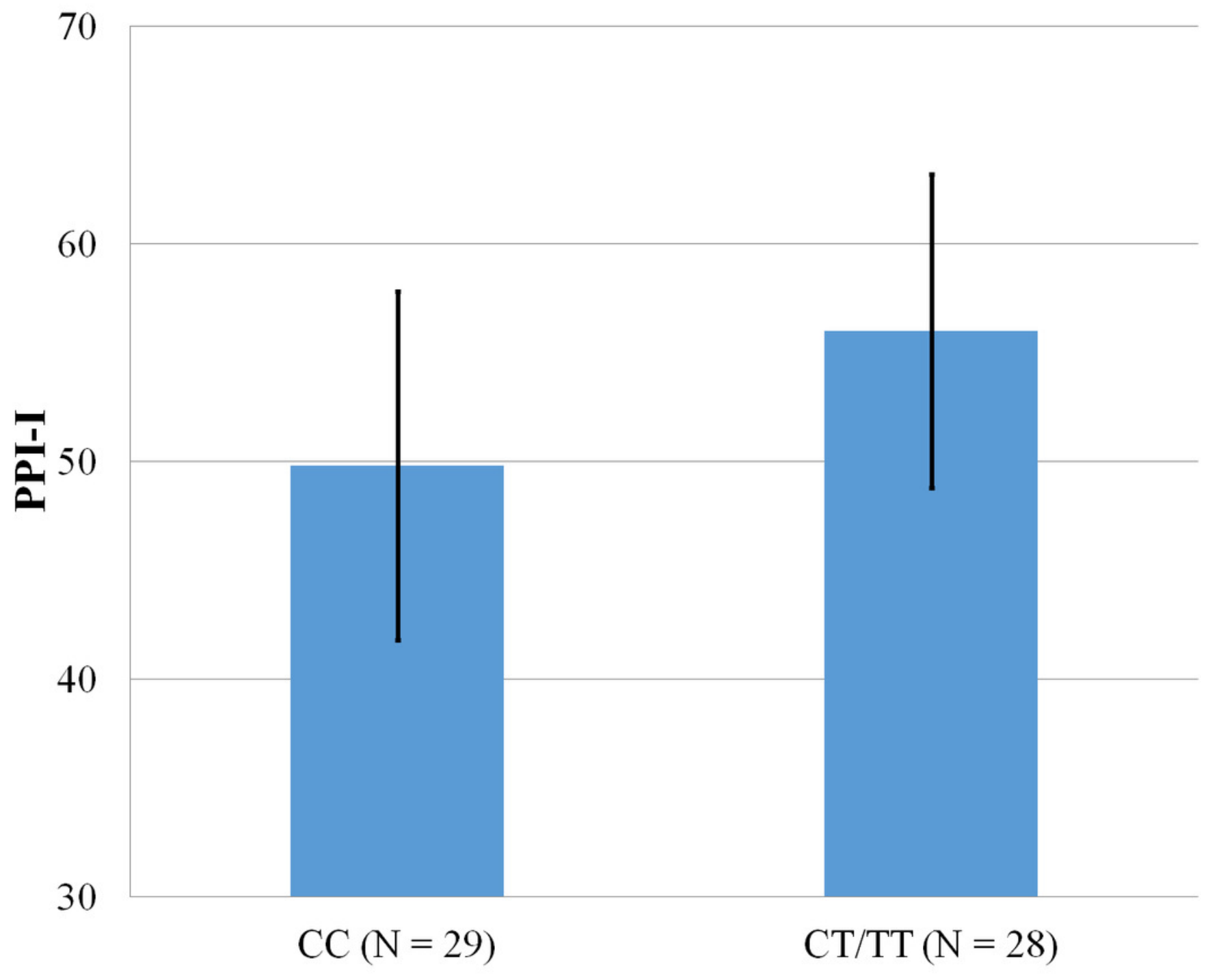


Figure 5

Mean number of moves to complete the Tower of Hanoi, within participants who completed the 5-disk tower, with error bars showing a 95\% confidence interval on rs5522 genotype.

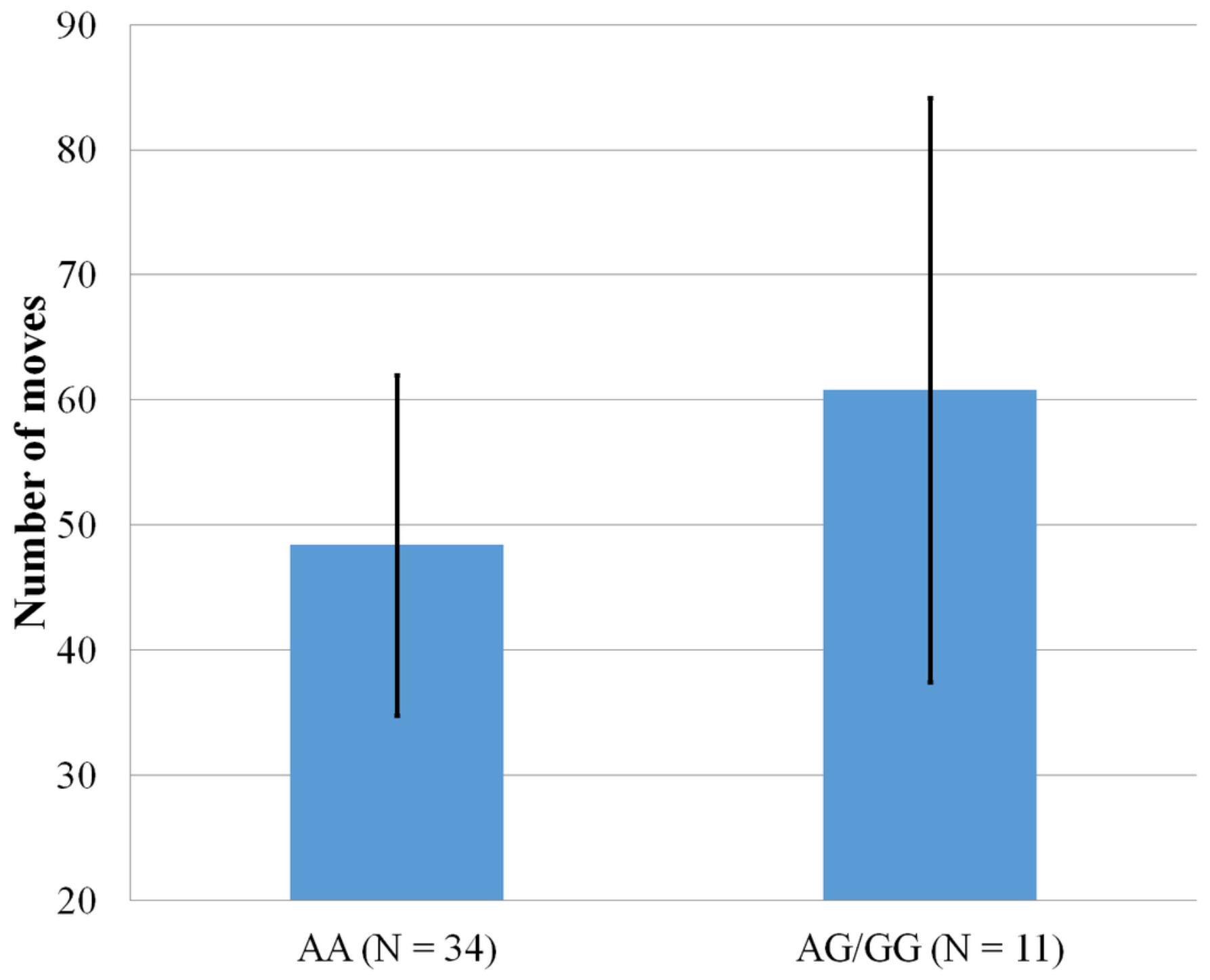

